\title{
Modelling the growth of the brown frog (Rana dybowskii)
}

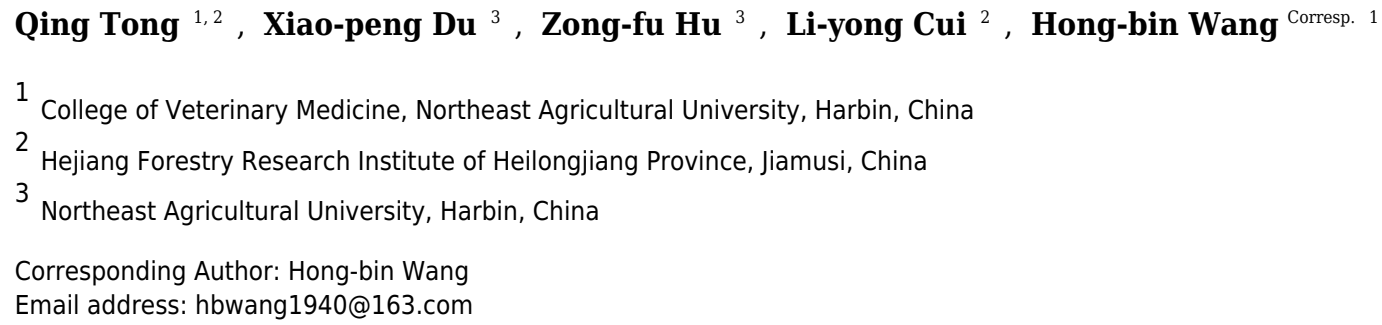

Well-controlled development leads to uniform body size and a better growth rate; therefore, the ability to determine the growth rate of frogs and their period of sexual maturity is essential for producing healthy, high-quality descendant frogs. To establish a working model that can best predict the growth performance of frogs, the present study examined the growth of one-year-old and two-year-old brown frogs (Rana dybowskii) from metamorphosis to hibernation (18 weeks) and out-hibernation to hibernation (20 weeks) under the same environmental conditions. Brown frog growth was studied and mathematically modelled using various nonlinear, linear, and polynomial functions. The model input values were statistically evaluated using parameters such as the Akaike's information criterion (AIC). The body weight/size ratio $\left(K_{\mathrm{wI}}\right)$ and Fulton's condition factor $(K)$ were used to compare the weight and size of groups of frogs during the growth period. The results showed that the third- and fourth-order polynomial models provided the most consistent predictions of body weight for age 1 and age 2 brown frogs, respectively. Both the Gompertz and third-order polynomial models yielded similarly adequate results for the body size of age 1 brown frogs, while the Janoschek model produced a similarly adequate result for the body size of age 2 brown frogs. The Brody and Janoschek models yielded the highest and lowest estimates of asymptotic weight, respectively, for the body weights of all frogs. The $K_{w l}$ value of all frogs increased from 0.40 to 3.18. The $K$ value of age 1 frogs decreased from 23.81 to 9.45 in the first 4 weeks. The $K$ value of age 2 frogs remained close to 10. Graphically, a sigmoidal trend was observed for body weight and body size with increasing age. The results of this study will be useful not only for amphibian research but also for frog farming management strategies and decisions. 


\section{Modelling the growth of the brown frog (Rana dybowskii)}

2 Qing Tong ${ }^{1,2}$, Xiao-peng $\mathrm{Du}^{3}$, Zong-fu $\mathrm{Hu}^{3}$, Li-yong Cui ${ }^{2}$, Hong-bin Wang ${ }^{1 *}$

3 ( ${ }^{1}$ College of Veterinary Medicine, Northeast Agricultural University, Harbin, China;

$4 \quad{ }^{2}$ Hejiang Forestry Research Institute of Heilongjiang Province, Jiamusi, China

$5 \quad{ }^{3}$ Northeast Agricultural University, Harbin, China)

6 Abstract: Well-controlled development leads to uniform body size and a better growth rate;

7 therefore, the ability to determine the growth rate of frogs and their period of sexual maturity is

8 essential for producing healthy, high-quality descendant frogs. To establish a working model that

9 can best predict the growth performance of frogs, the present study examined the growth of one-

10 year-old and two-year-old brown frogs (Rana dybowskii) from metamorphosis to hibernation (18

11 weeks) and out-hibernation to hibernation (20 weeks) under the same environmental conditions.

12 Brown frog growth was studied and mathematically modelled using various nonlinear, linear, and polynomial functions. The model input values were statistically evaluated using parameters

14 such as the Akaike's information criterion (AIC). The body weight/size ratio $\left(K_{\mathrm{wl}}\right)$ and Fulton's

15 condition factor $(K)$ were used to compare the weight and size of groups of frogs during the growth period. The results showed that the third- and fourth-order polynomial models provided

17 the most consistent predictions of body weight for age 1 and age 2 brown frogs, respectively.

${ }^{*}$ Corresponding author. Mailing address: College of Veterinary Medicine, Northeast Agricultural University, Harbin, 150030 , People's Republic of China.

Tel.: +86-451-55190470. Fax: +86-451-55190470.

E-mail: hbwang1940@163.com 
19 body size of age 1 brown frogs, while the Janoschek model produced a similarly adequate result

20 for the body size of age 2 brown frogs. The Brody and Janoschek models yielded the highest and

21 lowest estimates of asymptotic weight, respectively, for the body weights of all frogs. The $K_{w l}$

22 value of all frogs increased from 0.40 to 3.18. The $K$ value of age 1 frogs decreased from 23.81

23 to 9.45 in the first 4 weeks. The $K$ value of age 2 frogs remained close to 10 . Graphically, a

24 sigmoidal trend was observed for body weight and body size with increasing age. The results of

this study will be useful not only for amphibian research but also for frog farming management

strategies and decisions.

27

\section{Introduction}

Growth is one of the most important features of animals and can be defined as an increase in body weight or body dimensions over time or with age (Hossein-Zadeh 2015). The growth of frogs is often rapid before maturity but much slower after maturity because more resources are allocated to reproduction (Halliday \& Verrell 1988); adult female body length is often positively correlated with fecundity (Liao et al. 2015; Liao \& Lu 2009b). However, male and female frogs show similar trends in growth, body length, and age as the activity period decreases (Liao \& Lu 2012).

Currently, studies of amphibian development are mostly based on years (Liao et al. 2014; Martof 1956; Miaud et al. 1999). Several studies have mainly focused on the growth of captive bullfrogs (Mansano et al. 2017a; Mansano et al. 2012; Pereira et al. 2014). However, the study periods, which mainly involved the tadpole period, and the fattening periods of the bullfrog were relatively short. The growth records of frogs, especially those related to body size, based on 
40 weeks or days are very rare, especially for the stages from metamorphosis to sexual maturity.

41 During the stages from metamorphosis to sexual maturity, which are important stages in the life

42 of a frog, larval body length, the duration of the activity period, resource availability, and energy

43 storage vary with different growth patterns (Bruce 1993; Miaud et al. 1999).

Mathematical modelling is used in livestock production to assist technicians and researchers

in the development of animal breeding and nutrition programmes to improve the accuracy,

profitability, and sustainability of zootechnical activities (Pereira et al. 2014). The growth

performance of organisms under commercial aquaculture has been a determinant of economic

growth, so understanding the factors that limit the growth performance of brown frogs is

essential. The literature on frogs and other animals traditionally defines the relationship between

age and live weight as a nonlinear, sigmoidal (S-shaped) function (Kyriakopoulou-Sklavounou et

al. 2008; Liao \& Lu 2009a; Sarasola-Puente et al. 2011). However, our preliminary work showed

that logistic, Gompertz, and Von Bertalanffy models also fit experimental growth data well

(Tong et al. 2010), which led us to compare the ability of Handy growth curves, such as second-,

third-, and fourth-order polynomial functions, to model the growth of brown frogs with that of

polynomial functions. This is an important topic of research because various types of models

have different advantages and disadvantages. Polynomial models are much easier to handle than

nonlinear models because they are linear from a statistical perspective and can be easily solved

using linear regression if certain assumptions are valid. However, nonlinear mathematical

functions have been applied extensively in different species to describe body weight 
61

62

63

64

65

66

67

parameters with biological indications to facilitate both interpretation and comprehension of the phenomenon (Ersoy et al. 2006; Hossein-Zadeh 2015). Finally, a linear model (first-order polynomial) is especially attractive because of its easy interpretability (Tompić et al. 2011). The brown frog (Rana dybowskii) is mainly distributed in north-eastern China, and it is an important species with both medicinal and economic value (Hu et al. 2016). After years of research, we have developed a thorough understanding of the conditions necessary for $R$. dybowskii growth and have gained considerable experience in improving breeding conditions. In the present study, we built a suitable growth environment for $R$. dybowskii and investigated its growth in this habitat.

The purpose of this research is to explore the growth performance of brown frogs produced from a frog breeding system. Frog growth was studied and mathematically modelled using various nonlinear, linear, and polynomial functions. The model input values were statistically evaluated using strategies such as the least squares method, and correlations between the growth curves and the experimental data were analysed by the root mean square error (RMSE), the Durbin-Watson statistic (DW), the Bayesian information criterion (BIC), and Akaike's information criterion (AIC). The use of several nonlinear, linear, and polynomial functions to model frog body weight and size data in this research reflects the most comprehensive study of amphibians to date.

\section{Materials and methods}

\section{Ethics statement}


All frogs used in this study were handled in strict accordance with Northeast Agricultural

82

83

84

85

86

87

88

89

90

91

92

93

94

95

96

97

University (NEAU) IACUC protocols (IACUC\#09-012) and tissues-of-opportunity waivers were approved by NEAU. Tissues-of-opportunity are defined as samples collected (1) during the course of another project with an approved IACUC protocol from another institution; (2) during normal veterinary care provided by appropriately permitted facilities; or (3) from free-ranging animals at appropriately permitted facilities. No endangered or protected species were harmed during this study.

\section{Breeding environment}

The experiments were carried out from April to October of 2010 at a farm located in Jiankou Town $\left(46^{\circ} 51^{\prime} 54^{\prime \prime} \mathrm{N}, 130^{\circ} 17^{\prime} 32^{\prime \prime} \mathrm{E}\right.$; $80 \mathrm{~m}$ above sea level) owned by the Folin company in Jiamusi City, Heilongjiang Province, China. The area experiences a temperate continental monsoon climate with a long winter and a short summer, a frost-free season that typically lasts for $130 \mathrm{~d}$, average yearly precipitation of approximately $510 \mathrm{~mm}$, and an average temperature of $2.8^{\circ} \mathrm{C}$

The open-air breeding pens were enclosed by a sealed fence, a sprinkler was installed, and some low vegetation was planted. This simulated environment designed for rearing brown frogs resembled an actual forest habitat to ensure the necessary conditions for growth. Age 1 and age 2 brown frogs were reared separately in different pens, but all pens were maintained under the same conditions, including the air temperature, photoperiod, and air moisture as well as the construction materials and physical properties of the pen. The temperature and humidity were recorded every 2 hours by temperature-humidity metres. The air humidity in the pens varied 
102 slightly but was maintained at approximately $60 \sim 80 \%$ by spraying water into the air, and the 103 ground-level humidity of the pens was controlled within a range of $25 \sim 35 \%$. During the trial, the 104 average diurnal, maximum, and minimum temperatures recorded inside the facility were $18.73 \pm 3.73^{\circ} \mathrm{C}, 24.36 \pm 3.40^{\circ} \mathrm{C}$, and $13.10 \pm 2.29^{\circ} \mathrm{C}$, respectively. The temperature of the pens rarely exceeded $35^{\circ} \mathrm{C}$ due to ventilation and spraying, thus preventing stress from rapid changes in the

107

108

109

110

111

112

113

114

115 frogs' body temperature.

The age 1 and age 2 frogs were reared in 3 different breeding pens, each of which was approximately $80 \mathrm{~m}^{2}$ in size. The density of the age 1 brown frogs in the pens was $8 / \mathrm{m}^{2}$, and that of the age 2 brown frogs was $4 / \mathrm{m}^{2}$. During the experiments, the frogs and their behaviour were periodically examined. When the average temperature was above $10^{\circ} \mathrm{C}$ and the frogs were observed to be moving, we provided food (Tenebrio molitor). The frogs were fed once a day at 09:00, and the feeding amount was approximately $4 \%$ of their mean body weight. Insects in the natural environment were also available for consumption. The age 2 frogs used in this experiment had been cultured the previous year (2009) using breeding methods consistent with this experiment (2010). In the fall of 2009, the groups of age 2 frogs were placed in separate wintering ponds to avoid errors in discriminating between the different ages. The initial body weights for the age 1 and age 2 brown frogs were $3.47 \pm 0.74$ and $0.48 \pm 0.05 \mathrm{~g}$, respectively.

\section{Sample collection}

The snout-vent lengths (SVLs) and body weights of 40 brown frogs were measured each week. Callipers with a precision of approximately $0.02 \mathrm{~mm}$ were used to measure the body sizes 
122 (SVLs) of the specimens, and their body weights were measured using electronic scales (accurate

123 to $0.01 \mathrm{~g}$ ). Age 1 brown frogs included frogs in the developmental stages from metamorphosis to

124 out-hibernation in the second year, and age 2 brown frogs included frogs in the stages from out-

125 hibernation in the second year to out-hibernation in the third year. Additionally, the 1-year-old

126 brown frogs completed their metamorphosis by June $5^{\text {th }}$ and began eating between June $10^{\text {th }}$ and

127 June $15^{\text {th }}$. Brown frogs cannot eat after October $1^{\text {st }}$ due to low temperatures, which terminates

128 growth, so they must enter hibernation one month later. For age 2 brown frogs, the hibernation

129 period ended on May $15^{\text {th }}$, and they began to feed from May $25^{\text {th }}$ to June $1^{\text {st }}$ before entering

130 hibernation at the same time as the one-year-old brown frogs.

131 Males and females were mix-reared in the first year because the brown frogs did not exhibit

132 sexual dimorphism, but late in the second year, males and females were reared separately.

133 Growth functions

134 Frog growth was studied and mathematically modelled using various nonlinear, linear, and

135

136

137

138

139

140 polynomial functions. The nonlinear mathematical models included the logistic, Gompertz, von

Bertalanffy, Brody, Janoschek, and Richards models.

These models contain several common parameters and can associate any biological

meaning to each of them.

$\mathrm{W}$ is the measurement value ( $\mathrm{g}$ or $\mathrm{cm}$ ); $\mathrm{t}$ is the number of experimental weeks; $A$ is the body weight or length at maturity, and $B$ is an integration constant related to the initial weight of the 
141 animal, and $C$ is the maturation rate. The value $\mathrm{m}$ is the parameter that gives shape to the curve

142 by indicating where the inflection point occurs.

143 Logistic Model. The following equation describes the logistic (Fekedulegn et al. 1999)

144 growth model:

145

$$
W=A /\left(1+B e^{(-C t)}\right)
$$

147 growth model:

$$
W=A e^{-b \exp (-C t)}
$$

$$
W=A\left(1-B e^{(-C t)}\right)^{3}
$$

model:

$$
W=A\left(1-B e^{-C t \square}\right)
$$

$$
W=A-\left(A-W_{0}\right) e^{\left(-C t^{m}\right)}
$$

$$
W=A /\left(1+B \mathrm{e}^{(-\mathrm{C} t)}\right)^{1 / m}
$$




$$
W=d_{0}+\sum_{i=1}^{r} d_{i} \times t^{i}
$$
coefficient.

\section{Prediction consistency and quality}

$173 \quad R_{\text {adj }}^{2}=1-\left[\frac{n-1}{n-p}\right]\left(1-R^{2}\right)$

where $R^{2}$ is the coefficient of determination $\left(R^{2}=1-(\mathrm{RSS} / \mathrm{TSS})\right.$; the total sum of squares is denoted as TSS; and the residual sum of squares is denoted by RSS. Additionally, $\mathrm{n}$ and $\mathrm{p}$ are the number of observations or data points and the number of parameters in the equation, respectively. The coefficient of determination is denoted by $R^{2}$ and is a statistical measure of how well a regression line can approximate real data points. 
181 relationship between the general deviation around the average trend expressed by the growth

182 curve model, and its value lies between 0 and 1 . If the regression line of a model has a

183 coefficient of determination of 1 , it is considered a perfect approximation of the real data.

184 Therefore, the predictions of a model are considered satisfactory if the coefficient of

185 determination approaches unity.

186 The root mean square deviation (RMSD) is a particularly generalized type of standard

187 deviation that may occur among sets of observations and represents the sample standard

188 variation of differences between the values predicted by a model and the observed values

189 (Wikipedia 2017). Individual differences between predicted values and observed values are

190 referred to as residuals. The RMSE was calculated as follows:

$191 \quad$ RMSE $=\sqrt{\frac{\mathrm{RSS}}{\mathrm{n}-\mathrm{p}-1}}$

192 where RSS is the residual sum of squares; $\mathrm{n}$ is the total number of observations (data points); and

$193 \mathrm{p}$ is the number of parameters in the equation. The RSS is the squared sum of residuals, which is

194 the squared sum of the individual differences between values estimated from the model and the

195 observed values. The RSS determines the level of discrepancy between data and a model and is

196 therefore a vital criterion for model selection.

197 The RMSE value is a major criterion for analysing the predictability and adequacy of the

198 growth curve model of a desired function. Consequently, the growth curve of a function with the

199 smallest error in its RMSE is considered the most adequate model. 

implies a negative autocorrelation (Hossein-Zadeh 2015). The DW was calculated using the following formula:

$$
\mathrm{DW}=\frac{\sum_{t}^{n}\left(e_{t}-e_{t-1}\right)^{2}}{\sum_{t=1}^{n} e_{t}^{2}}
$$

where $e_{t}$ is the residual at time $t$, and $e_{t-1}$ is the residual at time $t-1$.

$$
\mathrm{AIC}=\mathrm{nln}(\mathrm{RSS})+2 \mathrm{p}
$$

AIC is a good statistic for comparing models or functions of varying complexity due to its ability to modify the RSS for a different range of parametric inputs in a particular model. A smaller AIC value implies greater consistency between the data and the model. The basic use of AIC is in model selection, which has its foundation in information theory and is carried out by implicit comparison of several models. Notably, if all the contrasting models fit the data poorly, AIC selection is affected but not disrupted during usage. 
219 logarithm ( $\log )$ of the most likely outcome with a term associated with the complexity of the

220 model, as shown in the following equation:

$221 \quad \mathrm{BIC}=\mathrm{n} \ln (\mathrm{RSS})+\mathrm{p} \ln (\mathrm{n})$

222 Similar to AIC values, smaller BIC values from the above expression suggest better consistency

223 between the data and the model.

224 The model input variables (parameters) were estimated, and statistical analyses were

225 conducted using R software version 2.14.2 (TEAM 2010). The nonlinear and linear models were

226 implemented by employing the nonlinear system (NLS) and linear modelling (LM) procedures.

227 The LM procedure involved the least-squares method, and the NLS procedure involved the

228 Gauss-Newton algorithm.

229 Body weight/size ratio

230 The body weight/size ratio $\left(K_{\mathrm{wl}}\right)$ was calculated as:

$231 K_{\mathrm{wl}}=\mathrm{W}^{*} \mathrm{~L}^{-1}$

232 where $\mathrm{W}$ is the body weight $(\mathrm{g})$, and $\mathrm{L}$ is the body length $(\mathrm{cm})$.

233 Fulton's condition factor

234 Fulton's condition factor $(K)$ was calculated as follows:

$235 K=100 \mathrm{~W}^{*} \mathrm{~L}^{-3}$

236 where $K$ is fatness $\left(\mathrm{g} / \mathrm{cm}^{3}\right)$; W is the weight $(\mathrm{g})$; and $\mathrm{L}$ is the length $(\mathrm{cm})$. Generally, larger

237 fatness values indicate that the frog is in good shape (Jin et al. 2015; Mozsár et al. 2015). 
The body weight/size ratio $\left(K_{\mathrm{wl}}\right)$ was calculated for each frog to assess its relative condition.

239 The numerical value of the ratio decreases as the condition of the individual improves (Heikura

240 1977).

241 Results

242 Growth curves

The body weights and body sizes of the age 1 animals from weeks 1 to 18 are illustrated in

244 Figures 1a and 2a, which show S-shaped or sigmoidal trends. Additionally, body weights and

245 sizes were assumed to be dependent on age (weeks) according to several growth models for all

246 frogs. The estimated growth curves were typically sigmoidal; in other words, the growth curves

247 were shaped in the form of the letter S (sigmoidal).

The observed body sizes and shapes of the age 2 frogs from week 1 to week 20 are shown

in Figures $1 b$ and $2 b$, with an obvious sigmoidal trend in body weights with increasing age.

Additionally, the estimated body size $(\mathrm{cm})$ as a function of age (weeks) was examined with several growth models for all frogs, and the original estimated growth curve was sigmoidal.

\section{Goodness of fit statistics for the growth models}

253

Low AIC, BIC, RMSE, and RMSE values and a high $R^{2}$ adj value indicate good fit of the

model to frog growth, which occurred for the same model.

255

The results showed that the third- and fourth-order polynomial models provided the most

256 consistent predictions of body weight for age 1 and age 2 brown frogs, respectively, and the

257 Gompertz and third-order polynomial models yielded similarly adequate results for the body size 
258 of age 1 brown frogs. Additionally, the Janoschek model generated a similarly adequate result

259 for the body size of two-year-old brown frogs due to decreases in the AIC, BIC, RMSE, and $R^{2}$ adj

260 values and an increase in the DW value relative to those of the other models (Tables 1 and 2).

261 Among all the nonlinear functions, the Richards model also provided the most satisfactory

262 results for the body weight of one-year-old frogs. Meanwhile, the most satisfactory model for the

263 body weight of age 2 frogs was the logistic model, and both the Gompertz and the Janoschek

264 models provided the most consistent predictions of body size for age 1 and 2 frogs, respectively,

265 due to decreases in the AIC, BIC, and RMSE values and increases in the DW and $R^{2}$ adj values

266 compared to those of the other models (Tables 1 and 2).

The DW of all models was between 0.22 and 0.54 . The linear model had the smallest DW

values among all considered models of body weight and body size, and the fourth-order

polynomial function presented the largest sets of values with the highest DW values among all

considered models of the body weight and body size of age 2 frogs (Tables 1 and 2).

271

The $R^{2}$ and $R^{2}$ adj values of all models showed slight discrepancies between the models of frogs. 
For the linear model, $\mathrm{d}_{0}$ (intercept) is interpreted as an estimate of initial body weights or

280

281

282

283

284

285

286

287

288

289

290

291

292

293

294

295

296

297

298

299

body sizes, although parameter $\mathrm{d}_{1}$, which is defined as an average body weight or body size,

changed over the course of a week. Table 4 shows negative $d_{1}$ values for the body weight of age

1 frogs, indicating imprecise estimates of this parameter.

\section{Asymptotic weight and maturation rate}

The parameter A is an estimate of asymptotic weight, which can be described as the mature or adult weight. The Brody and Janoschek models yielded the highest and lowest estimates of A, respectively, for the body weights of all frogs. The Janoschek growth model is similar to the Richards model in terms of the level of flexibility (Tables 3 and 5).

Another parameter of interest is the speed of growth to the asymptotic weight, which is represented by the parameter $\mathrm{C}$ and is called the maturation rate. In this research, age 2 brown frogs generally showed greater values for this parameter than the age 1 frogs (Tables 3 and 5).

\section{$K_{\text {wl }}$ value and $K$ value}

Figure 3 shows that the $K_{\mathrm{wl}}$ values of both the age 1 and 2 frogs increased with growth, and no major changes were observed during the first 4 weeks or from weeks 13 to 18 . We can also see that the growth of the frogs was concentrated during weeks 4 to 14 . The $K_{\mathrm{wl}}$ value of the 1 year-old frogs increased from 0.40 to 1.08 , and the $K_{\mathrm{wl}}$ value of the age 2 frogs increased from 1.08 to 3.18 .

Figure 4 shows that the $K$ value of the 1-year-old frogs exhibits uncertain variation, and it decreased from 23.81 to 9.45 in the first 4 weeks, indicating development of growth characteristics after metamorphosis. The $K$ values increased before declining. The $K$ value of the 
300

301

302

303

304

305

306

307

308

309

310

311

312

313

314

315

316

317

318

319

age 2 frogs decreased from 10.54 to 9.10 within 6 weeks and then increased until week 15 before decreasing again.

\section{Discussion}

\section{Growth of the brown frogs}

The growth of the brown frog, similar to all animals, depends on the genotype-environment interaction (Mansano et al. 2017a). Animal growth is associated with genetics, biotype, race, weight, age, and body state. However, culture management and nutrition supply are also the key factors in frog culture (Mansano et al. 2017b; Olvera-Novoa et al. 2007). Modelling animal growth curves is necessary for optimizing the management and efficiency of animal production (Köhn et al. 2007), and growth modelling provides many benefits for frog production. Many similar growth modelling studies of pigs (Köhn et al. 2007; Wellock et al. 2004), sheep (Hossein-Zadeh 2015), poultry (Rizzi et al. 2013), fish (Baer et al. 2011), crabs (Durán et al. 2013), and bullfrogs (Mansano et al. 2017a; Mansano et al. 2012; Pereira et al. 2014) are available. Pereira et al. tested Gompertz and logistic models for captive bullfrogs during the fattening phase (the terrestrial phase) (Pereira et al. 2014). In the aquatic phase, different models were applied for evaluation and simulation of bullfrog tadpole growth (Mansano et al. 2016; Mansano et al. 2012). Monitoring the growth and development of brown frogs is essential to better understand the general relationship between production and management on frog farms (Pereira et al. 2014) as well as the relationships between growth and age or growth and feeding over time. 
Puente et al. 2011), and research based on days-old or weeks-old animals are rare (Sarasola-

Puente et al. 2011; Tessa et al. 2017) even though this scale is very important to studies of froglet

growth. However, skeletochronological methods have many deficiencies in terms of studying the

growth of amphibians based on days or weeks and many animals must be sacrificed and the work is too difficult and time-intensive.

The artificial breeding technology used for frogs in this study is specific to $R$. dybowskii,

which was domesticated in China (Bing 2012). Similar to many fully terrestrial frogs in the

Temperate Zone, Rana dybowskii lives on land in summer but hibernates in water in the winter.

In this study, we built suitable habitats for $R$. dybowskii and investigated its growth in breeding

initiation and termination (for hibernation) dates were determined. The ages of the frogs were

known from management of the frog farm. The above time points are pertinent to the intrinsic

growth rate, which provides a better understanding of growth over weeks or the explicit

relationship between growth and feeding.

(Iturra-Cid et al. 2010) from metamorphosis to sexual maturity because frogs can reach more 
342 showing a slow rate of increase in the initial stage before accelerating at the metaphase and then

343 slowing again at a later stage (Hedeen 1972; Martof 1956). From the results, we can see that

344 body weight increased throughout the lifetimes of the animals, with only slight decreases in later 345 periods.

The most rapid rate of growth in body weight and size occurs in the first 2 years (Iturra-Cid

347 et al. 2010), and the intrinsic growth rates are higher in the first year than those at other times

348 (Semlitsch et al. 1988). In the first year before hibernation, a weight gain of approximately 7.02-

349 times the initial weight was recorded, and the weight increased during the second year to approximately 5.41-times that of the first year.

351 As shown in Figures 1 and 2, growth in terms of body length was faster than that of body weight in the initial stage. In Figures 3 and 4, the relative fatness index of the brown frogs is low; the growth rates for body weight and body size were unsynchronized, and the growth of body weight was slower than that of body size.

In brown frog breeding, growth requires a reasonable food supply and balanced nutrition, but the frogs often showed dietary deficiencies from the $4^{\text {th }}$ to the $10^{\text {th }}$ week after initiating feeding (Densmore \& Green 2007). Therefore, vitamins A and D must be supplied during this period (Ogilvy et al. 2012). Furthermore, growth in terms of body size began prior to the increase in body weight, and growth in terms of body weight started after body size stopped increasing (Von Bertalanffy 1957). The final weight was restricted by body volume and was shown to be self-inhibiting. 
occurs with the gradual decline in temperature before hibernation. The brown frog can

hibernation, and they sustain themselves by utilizing energy stored in the liver and fat.

\section{Making sense of the parameters}

$$
\text { Knowledge regarding how parameters, such as the growth rate, differ among all }
$$

developmental stages in frog breeding is important for formulating culture management strategies. Management must be appropriate for populations at different stages.

In this study, the logistic and Gompertz functions were used because of their ability to simply describe vital factors. Some of these simple descriptions include modelling the growth rate as a basic function of size, continuous growth, asymptotes, parameters with biological points, points of inflection, and sigmoidal trends. According to (Richards 1959), the 4-parameter flexible inflection points of the Richards function that are suitable for modelling animal growth were developed by modifying the logistic and Gompertz functions (Richards 1959). In contrast, the Janoschek function (Janoschek 1957) can mainly be used to describe the postnatal growth of individuals, but this function is also flexible in terms of its points of inflection, all of which are desirable properties in nonlinear growth models (Wellock et al. 2004). The fourth-order polynomial model was selected due to its similarity to nonlinear growth models. In this study of brown frogs, the Richards function was found to be most suitable for modelling growth according to the low AIC values, and this conclusion was also determined in a study of the 
383 growth of ducks and other poultry (Knižetova et al. 1991) after evaluating other studies that used

384 the Richards, logistic, and Gompertz functions to model poultry growth. The $R^{2}$ adj values for the

385 Richards growth functions were slightly higher than those of the remaining nonlinear models,

386 which all had similar $R^{2}$ adj values; the Richards growth function also showed the lowest AIC

387 values. The $R^{2}$ adj value measures linearity and is consequently a more suitable and appropriate

388 factor for linear models.

389 According to Tompić et al (2011), the calculated AIC and $R^{2}$ adj values suggest that the

390

391

392

393

394

395

396

397

398

399

400

401

402

403

fourth-order polynomial model was more suitable. The estimated $\mathrm{A}$ and $\mathrm{C}$ parameter values are

interpreted as mature body weight and the instantaneous relative growth rate, respectively.

A linear model, unlike nonlinear models, lacks parameters with biological meaning (Brown

et al. 1976), but nonlinear models with such parameters can be linearized and evaluated by linear

regression (Bates \& Hunter 1985). The results of the current study suggest that the logistic model is adequate for explaining brown frog growth in terms of both body size and body weight, but further research is required to fully understand the growth of brown frogs in China. Ideally, these studies would involve large frog data sets, each with a similar number of body weight records collected and regulated across intervals that are sufficiently similar to permit sufficient sample sizes.

Obtaining frog descendants with rapid growth and sexual maturity rates (Dmitriew 2011) requires understanding the growth rate, implying that a process exists that alters the curvilinear growth of frogs. There are two strategies for changing growth curves: altering the parameters of a curve while leaving its basic configuration untouched, and changing the basic shape of the 
404

405

406

407

408

409

410

411

412

413

414

415

416

417

418

419

420

421

422

curve. The first strategy is the best approach for mature body weight, and the latter strategy is

more desirable for the growth rate alone. The second strategy is known to apply to frog culture;

the growth in the early stage is exponential, and the frog grows more rapidly if the process is

strongly implemented.

\section{The fitness of the captive environment}

Rana dybowskii is a rare species among breeding frogs. It usually lives on land in a forest

environment during its terrestrial stage, which differs from other frogs that exhibit a more

typical, amphibious lifecycle.

For Rana dybowskii, an amphibian that lives in terrestrial habitats, influencing the micro-

climate factors of the captive environment was easy, which is unlike cultivation of other frogs or

snakes and turtles that have complex lives both in water and on land. The rearing cycle of Rana

dybowskii was up to 2-3 years long, and the frog has the characteristics of "three adaptions and

nine inadaptations"; the three adaptions are gloomy, dampness, and clean, and the nine

inadaptations are high light, rain, dry, wind, high temperature, predators, dirty, noise, and off-

flavour. These features reflect the high risk of frog culture due to complicated breeding

technology and high morality. High-density breeding is the main factor affecting the occurrence

of disease and high morality. The present study was conducted at a site within the natural

distribution of $R$. dybowskii, and the density of the captive frogs was relatively low, which can

largely prevent the occurrence of disease and ensure normal growth of the brown frog. 
424 the quality and quantity of food and health status (Mansano et al. 2017a). Culturing frogs in an

425 artificial environment is difficult even if some aspects of the habitat, such as temperature and

426 humidity, satisfy the needs of the animals. For example, the average diurnal temperature

427 recorded inside the facility was $18.73 \pm 3.73^{\circ} \mathrm{C}$. The temperature of the pens rarely exceeded

$42835^{\circ} \mathrm{C}$ during the trial. If other necessary parameters for optimal culturing are not satisfied, such as

429 density and food composition, growth and health status may change. Typically, animals with free

430 access to food mature faster and grow to larger sizes, and when resource levels decline, animals

431 tend to grow more slowly, reach maturity later, and grow to smaller sizes (Day \& Rowe 2002;

432 Dmitriew 2011; Lind et al. 2008). The breeding system used in this experiment included an

433 appropriate culturing environment, sufficient quality and quantity of food, and proper

434 management, fulfilling the basic requirements for frog growth. The $K, K_{\mathrm{wl}}$, and fatness of the

435 cultured frogs were greater than those of wild frogs or frogs grown in a much more natural

436 environment (Wang et al. 2009), suggesting that frogs can live in a cultured environment and

437 still obtain a not bad nutrition status.

438

439

440

441

442

\section{Conclusion}

The growth of brown frogs was studied, and a mathematical model was developed using various nonlinear, linear, and polynomial functions. However, third- and fourth-order polynomial models provided the best fit for growth curves of body weight for age 1 and age 2 brown frogs, respectively. Both the Gompertz and third-order polynomial models yielded similarly adequate 
443 results for the body size of age 1 brown frogs, while the Janoschek model produced a similarly

444 adequate result for the body size of two-year-old brown frogs due to lower RMSE, AIC, and BIC

445 values and greater $R^{2}$ adj values than those of the other models. The results will be useful for

446 amphibian research, and the growth curves will inform frog farm management strategies and

447 decision-making regarding the culling of poor producers and the selection of highly productive

animals. Furthermore, the relationship between growth characteristics and environmental

449 changes has yet to be revealed.

450

451

452

453

454

455

456

457

458

459

460

461

462

463

464

465

466

467

468

469

470

471

472

473

474

\section{References}

Baer A, Schulz C, Traulsen I, and Krieter J. 2011. Analysing the growth of turbot (Psetta maxima) in a commercial recirculation system with the use of three different growth models. Aquaculture International 19:497-511.

Bates DM, and Hunter W. 1985. Nonlinear models. Encyclopedia of Statistical Sciences.

Bing C. 2012. Stocking Technology of Semi-artificial Breeding About Heilongiiang Forest Frog. Forest By-Product and Speciality in China 1:005.

Brown J, Fitzhugh H, and Cartwright T. 1976. A comparison of nonlinear models for describing weight-age relationships in cattle. Journal of Animal Science 42:810-818.

Bruce RC. 1993. Sexual size dimorphism in desmognathine salamanders. Copeia:313-318.

Day T, and Rowe L. 2002. Developmental thresholds and the evolution of reaction norms for age and size at lifehistory transitions. The American Naturalist 159:338-350.

Densmore CL, and Green DE. 2007. Diseases of amphibians. Ilar Journal 48:235-254.

Dmitriew CM. 2011. The evolution of growth trajectories: what limits growth rate? Biological Reviews 86:97-116.

Durán J, Palmer M, and Pastor E. 2013. Growing reared spider crabs (Maja squinado) to sexual maturity: The first empirical data and a predictive growth model. Aquaculture s 408-409:78-87.

Ersoy IE, Mendes M, and Aktan S. 2006. Growth curve establishment for American Bronze turkeys. ARCHIV FUR TIERZUCHT 49:293.

Fekedulegn D, Mac Siurtain MP, and Colbert JJ. 1999. Parameter estimation of nonlinear growth models in forestry. Ajr American Journal of Roentgenology 168:1465-1471.

Gille U, and Salomon FV. 1995. Bone growth in ducks through mathematical models with special reference to the Janoschek growth curve. Growth Development \& Aging Gda 59:207-214.

Hadeler. 1974. Mathematik fur Biologen K.P. Hadeler.

Hedeen SE. 1972. Postmetamorphic growth and reproduction of the mink frog, Rana septentrionalis Baird. Copeia:169-175.

Heikura K. 1977. Effects of climatic factors on the field vole Microtus agrestis. Oikos:607-615. 
475

476

477

478

479

480

481

482

483

484

485

486

487

488

489

490

491

492

493

494

495

496

497

498

499

500

501

502

503

504

505

506

507

508

509

510

511

512

513

514

Hossein-Zadeh NG. 2015. Modeling the growth curve of Iranian Shall sheep using non-linear growth models. Small Ruminant Research 130:60-66.

Hu R, Xi L, Cao Q, Yang R, Liu Y, Sheng X, Han Y, Yuan Z, Guo Y, and Weng Q. 2016. The expression of prostaglandin-E2 and its receptor in the oviduct of Chinese brown frog (Rana dybowskii). Prostaglandins \& Other Lipid Mediators 124:9-15.

Iturra-Cid M, Ortiz JC, and Ibargüengoytía NR. 2010. Age, size, and growth of the Chilean frog Pleurodema thaul (Anura: Leiuperidae): latitudinal and altitudinal effects. Copeia 2010:609-617.

Janoschek A. 1957. Das reaktionskinetische Grundgesetz und seine Beziehungen zum Wachstums-und Ertragsgesetz. Statistische Vierteljahresschrift 10:25-37.

Jin S, Yan X, Zhang H, and Fan W. 2015. Weight-length relationships and Fulton's condition factors of skipjack tuna (Katsuwonus pelamis) in the western and central Pacific Ocean. PeerJ 3:e758.

Knižetova H, Hyanek J, Kniže B, and Prochazkova H. 1991. Analysis of growth curves of fowl. II. Ducks. British poultry science 32:1039-1053.

Köhn F, Sharifi A, and Simianer H. 2007. Modeling the growth of the Goettingen minipig. Journal of Animal Science 85:84-92.

Kyriakopoulou-Sklavounou P, Stylianou P, and Tsiora A. 2008. A skeletochronological study of age, growth and longevity in a population of the frog Rana ridibunda from southern Europe. Zoology 111:30-36.

Liao W, and Lu X. 2012. Adult body size $=\mathrm{f}$ (initial size + growth rate $\times$ age): explaining the proximate cause of Bergman's cline in a toad along altitudinal gradients. Evolutionary Ecology 26:579-590.

Liao WB, Liu WC, and Merilä J. 2015. Andrew meets Rensch: sexual size dimorphism and the inverse of Rensch's rule in Andrew's toad (Bufo andrewsi). Oecologia 177:389-399.

Liao WB, and Lu X. 2009a. Age structure and body size of the Chuanxi Tree Frog Hyla annectans chuanxiensis from two different elevations in Sichuan (China). Zoologischer Anzeiger 248:255-263.

Liao WB, and Lu X. 2009b. Sex recognition by male Andrew's toad Bufo andrewsi in a subtropical montane region. Behavioural Processes 82:100.

Liao WB, Lu X, and Jehle R. 2014. Altitudinal variation in maternal investment and trade-offs between egg size and clutch size in the Andrew's toad. Journal of Zoology 293:84-91.

Lind MI, Persbo F, and Johansson F. 2008. Pool desiccation and developmental thresholds in the common frog, Rana temporaria. Proceedings of the Royal Society of London B: Biological Sciences 275:1073-1080.

Lindberg MS, Schmidt JH, and Walker J. 2015. History of multimodel inference via model selection in wildlife science. The Journal of Wildlife Management 79:704-707.

López JA, Antoniazzi CE, Llanes RE, and Ghirardi R. 2017. Age structure, growth pattern, sexual maturity, and longevity of Leptodactylus latrans (Anura: Leptodactylidae) in temperate wetlands. Amphibia-Reptilia 38:371-379.

Mansano CFM, Macente BI, Khan KU, do Nascimento TMT, da Silva EP, Sakomura NK, and Fernandes JBK. 2017a. Morphometric Growth Characteristics and Body Composition of Fish and Amphibians. New Insights into Morphometry Studies: InTech.

Mansano CFM, Macente BI, Nascimento TMT, Pereira MM, and Takahashi LS. 2017b. Amino acid digestibility of animal protein ingredients for bullfrogs in different phases of post-metamorphic development. Aquaculture Research 48. 
515 Mansano CFM, Pereira MM, Peruzzi NJ, Macente BI, De Stéfani MV, Pereira MM, Peruzzi NJ, Macente BI, and 516 De Stéfani MV. 2016. Nonlinear models for morphometric analysis in Bullfrog Tadpoles. Revbrassaúde 517 Prodanim 17:280-290.

518 Mansano CFM, Stéfani MVD, Pereira MM, and Macente BI. 2012. Non-linear growth models for bullfrog tadpoles. Ciência e Agrotecnologia 36:454-462.

Martof B. 1956. Growth and development of the green frog, Rana clamitans, under natural conditions. American Midland Naturalist:101-117.

Miaud C, Guyétant R, and Elmberg J. 1999. Variations in life-history traits in the common frog Rana temporaria (Amphibia: Anura): a literature review and new data from the French Alps. Journal of Zoology 249:61-73.

Mozsár A, Boros G, Sály P, Antal L, and Nagy SA. 2015. Relationship between Fulton's condition factor and proximate body composition in three freshwater fish species. Journal of Applied Ichthyology 31:315-320.

Ogilvy V, Preziosi R, and Fidgett A. 2012. A brighter future for frogs? The influence of carotenoids on the health, development and reproductive success of the red-eye tree frog. Animal Conservation 15:480-488.

Olvera-Novoa MA, Ontiveros-Escutia VM, and Flores-Nava A. 2007. Optimum protein level for growth in juvenile bullfrog (Rana catesbeiana Shaw, 1802). Aquaculture 266:191-199.

Pereira MM, Mansano CFM, Silva EPd, and Stéfani MVD. 2014. Growth in weight and of some tissues in the bullfrog: fitting nonlinear models during the fattening phase. Ciência e Agrotecnologia 38:598-606.

Richards F. 1959. A flexible growth function for empirical use. Journal of experimental Botany 10:290-301.

Rizzi C, Contiero B, and Cassandro M. 2013. Growth patterns of Italian local chicken populations. Poultry Science 92:2226-2235.

Sarasola-Puente V, Gosá A, Oromí N, Madeira MJ, and Lizana M. 2011. Growth, size and age at maturity of the agile frog (Rana dalmatina) in an Iberian Peninsula population. Zoology 114:150-154.

Semlitsch RD, Scott DE, and Pechmann JH. 1988. Time and size at metamorphosis related to adult fitness in Ambystoma talpoideum. Ecology 69:184-192.

TEAM RC. 2010. R: A language and environment for statistical computing. R Foundation for Statistical Computing, Vienna, Austria. ISBN 3-900051-07-0, URL: http://www. R-project. org.

Tessa G, Crottini A, Giacoma C, Guarino FM, and Randrianirina JE. 2017. Comparative longevity and age at sexual maturity in twelve rainforest frogs of the genera Boophis, Gephyromantis, and Mantidactylus (Anura: Mantellidae) from Madagascar. Phyllomedusa: Journal of Herpetology 16:13-21.

Tompić T, Dobša J, Legen S, Tompić N, and Medić H. 2011. Modeling the growth pattern of in-season and offseason Ross 308 broiler breeder flocks. Poultry Science 90:2879-2887.

Von Bertalanffy L. 1957. Quantitative laws in metabolism and growth. The quarterly review of biology 32:217-231.

Wellock I, Emmans G, and Kyriazakis I. 2004. Describing and predicting potential growth in the pig. Animal Science 78:379-388.

Wikipedia C. 2017. Root mean square deviation. Available at https://en.wikipedia.org/wiki/Root-meansquare deviation.

Yang XT, Ying L, Zhou XH, and Wang H. 2011. Skeletachronological Study on Growth Regular of the Dybowski's Frog. Journal of Economic Animal 3: 013.

Ziegler L, Arim M, and Bozinovic F. 2016. Intraspecific scaling in frog calls: the interplay of temperature, body size and metabolic condition. Oecologia 181:673-681. 
555 
Figure 1

Observed body weights for brown frogs ages 1 and 2 .

a, the body weight of 1-yr-old frog within 1-18 weeks. The Polynomial function of third-order was the best in refitting in the equation. Six nonlinear functions was the best fitting in Richards analysis. b, the body weight of 2-yr-old frog within 1-20 weeks. The Polynomial function of fourth-order was the best in refitting in the equation. Logistic was the best fitting in Six nonlinear functions.
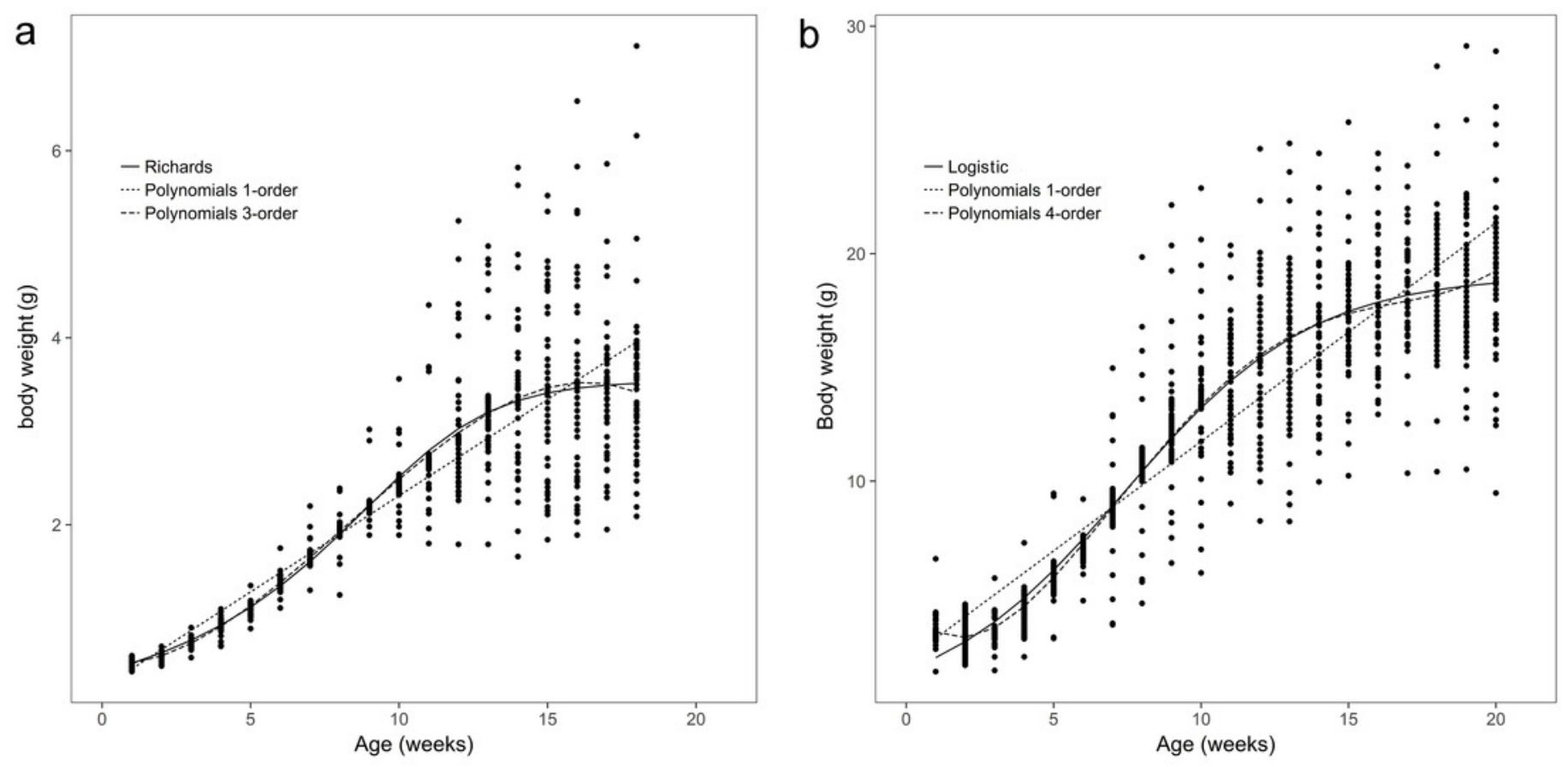
Figure 2

Observed body sizes for brown frogs ages 1 and 2 .

a, the body length of 1-yr-old frog within 1-18 weeks. Both the Gompertz and third-order polynomial models yielded similarly adequate results for the body size of age 1 brown frogs. b, the body length of 2-yr-old frog within 1-20 weeks. The Janoschek function was the best in refitting in the equation. The Polynomial function of fourth-order was the best in refitting in the Polynomial models.
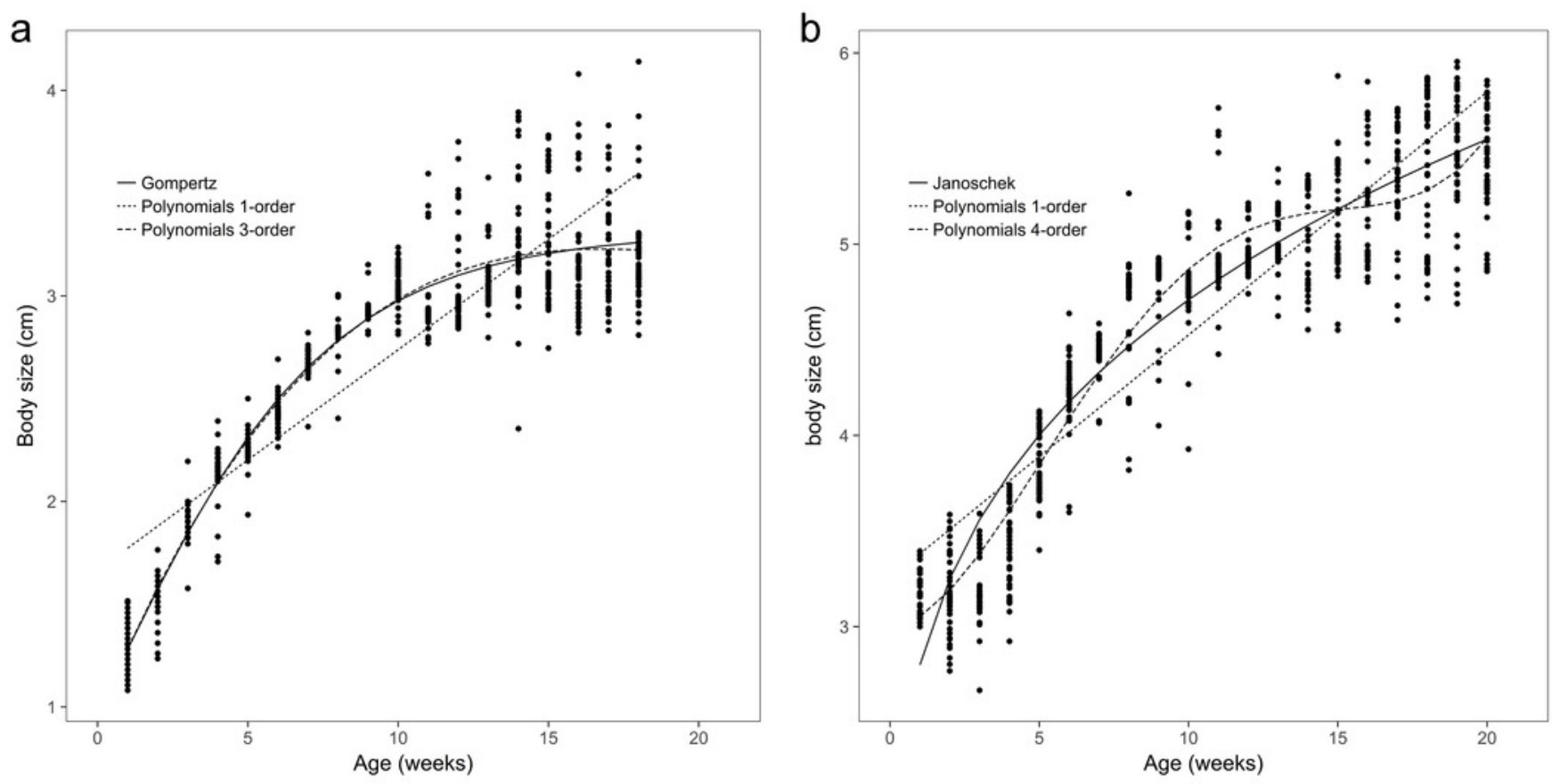


\section{Figure 3}

Variation in the weight/length index $\left(\mathrm{K}_{\mathrm{w}}\right)$ of brown frogs of different ages (mean $\pm \mathrm{SE}$ ).

Body weight/size ratio $\left(\mathrm{K}_{\mathrm{w}}\right)$ was calculated as: $\mathrm{K}_{\mathrm{wl}}=\mathrm{W}^{*} \mathrm{~L}^{-1}$, Where $\mathrm{W}$ is the weight $(\mathrm{g}), \mathrm{L}$ is the length $(\mathrm{cm}) . \mathrm{a}$, the change of $\mathrm{KWl}$ value with the time in 1-yr-old frog. $\mathrm{b}$, the change of $\mathrm{KWl}$ value with the time in 2-yr-old frog.
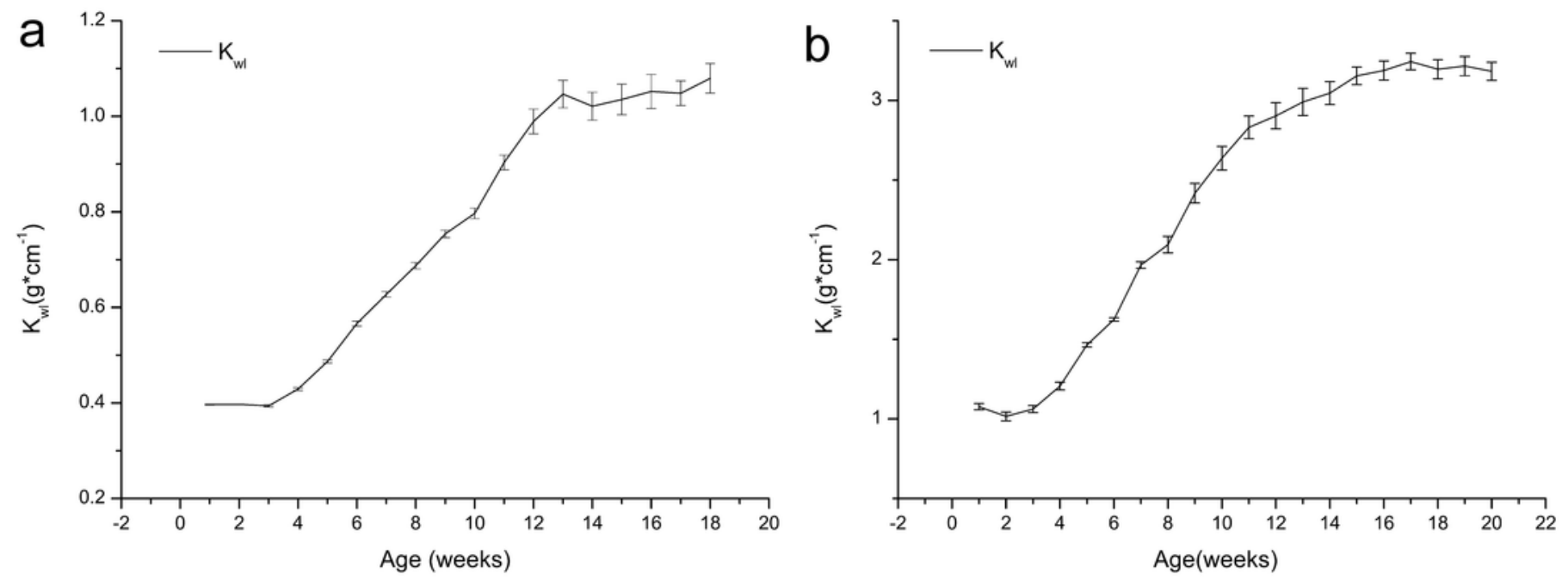


\section{Figure 4}

Variation in the relative fatness of brown frogs of different ages (mean $\pm S E$ ).

$\mathrm{K}=100 \mathrm{~W} * \mathrm{~L}^{-3}$, Where $\mathrm{K}$ is fatness $\left(\mathrm{g} / \mathrm{cm}^{3}\right)$, and $\mathrm{W}$ is the weight $(\mathrm{g}), \mathrm{L}$ is the length $(\mathrm{cm})$.

Fatness in general larger values, frog is in good shape, a, the change of $K$ value with the time in 1-yr-old frog. $b$, the change of $K$ value with the time in 2-yr-old frog.
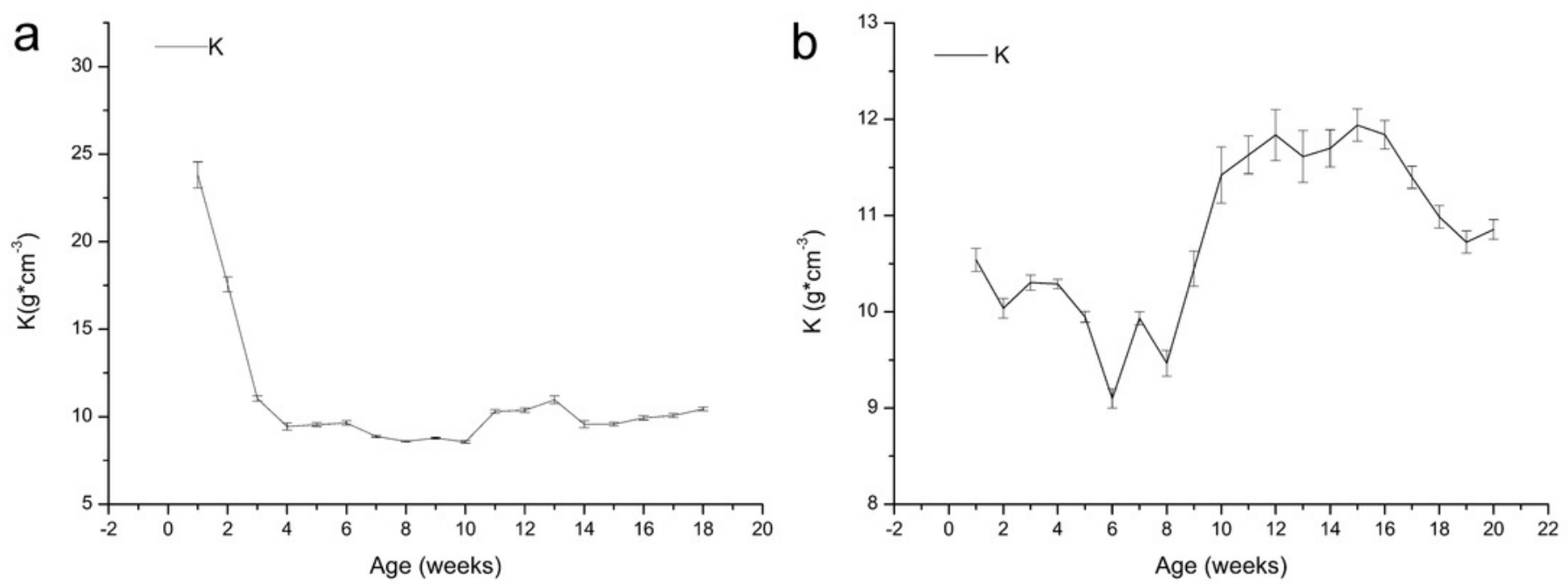


\section{Table $\mathbf{1}$ (on next page)}

Comparison of the goodness of fit for different growth curves of body weight in brown frogs. 
Manuscript to be reviewed

\begin{tabular}{|c|c|c|c|c|c|c|c|c|}
\hline \multirow[t]{2}{*}{ Criterion/model } & \multicolumn{4}{|c|}{ Age 1} & \multicolumn{4}{|c|}{ Age 2} \\
\hline & RMSE & DW & AIC & BIC & RMSE & DW & AIC & BIC \\
\hline Logistic & 0.577 & 0.525 & 1256.063 & 1274.980 & 2.678 & 0.533 & 3850.184 & 3870.923 \\
\hline Gompertz & 0.584 & 0.517 & 1271.963 & 1290.280 & 2.705 & 0.526 & 3866.584 & 3885.322 \\
\hline Von Bertalanffy & 0.587 & 0.512 & 1281.243 & 1299.560 & 2.729 & 0.518 & 3880.586 & 3899.324 \\
\hline Brody & 0.598 & 0.497 & 1307.812 & 1326.129 & 2.808 & 0.493 & 3926.194 & 3944.933 \\
\hline Richards & 0.575 & 0.527 & 1251.942 & 1274.838 & 2.679 & 0.533 & 3851.877 & 3875.300 \\
\hline Janoschek & 0.599 & 0.482 & 1310.328 & 1328.645 & 2.710 & 0.523 & 3869.361 & 3888.100 \\
\hline Linear & 0.609 & 0.487 & 1332.386 & 1346.124 & 2.955 & 0.449 & 4007.023 & 4021.077 \\
\hline Polynomials, second & 0.596 & 0.499 & 1302.462 & 1320.779 & 2.783 & 0.499 & 3911.700 & 3930.438 \\
\hline Polynomials, third order & 0.575 & 0.524 & 1251.922 & 1274.818 & 2.715 & 0.513 & 3873.511 & 3896.934 \\
\hline Polynomials, fourth order & 0.576 & 0.525 & 1253.712 & 1281.187 & 2.660 & 0.545 & 3841.885 & 3869.992 \\
\hline
\end{tabular}




\section{Table 2 (on next page)}

Comparison of the goodness of fit for different growth curves of body size in brown frogs. 


\begin{tabular}{|c|c|c|c|c|c|c|c|c|}
\hline \multirow[t]{2}{*}{ Criterion/model } & \multicolumn{4}{|c|}{ Age 1} & \multicolumn{4}{|c|}{ Age 2} \\
\hline & RMSE & DW & AIC & $\mathrm{BIC}$ & RMSE & DW & AIC & $\mathrm{BIC}$ \\
\hline Logistic & 0.192 & 0.508 & -332.067 & -313.750 & 0.269 & 0.382 & 173.674 & 192.412 \\
\hline Gompertz & 0.191 & 0.512 & -333.399 & -315.082 & 0.269 & 0.382 & 173.674 & 192.412 \\
\hline Von Bertalanffy & 0.192 & 0.511 & -330.803 & -312.486 & 0.273 & 0.372 & 196.570 & 215.308 \\
\hline Brody & 0.193 & 0.505 & -319.451 & -301.134 & 0.276 & 0.366 & 212.456 & 231.195 \\
\hline Richards & 0.191 & 0.511 & -332.305 & -309.409 & 0.267 & 0.386 & 161.459 & 184.882 \\
\hline Janoschek & 0.192 & 0.512 & -332.716 & -314.399 & 0.256 & 0.398 & 96.460 & 115.199 \\
\hline Linear & 0.299 & 0.217 & 308.759 & 322.497 & 0.354 & 0.220 & 611.641 & 625.695 \\
\hline Polynomials, second & 0.194 & 0.489 & -317.717 & -299.400 & 0.274 & 0.367 & 200.948 & 219.687 \\
\hline Polynomials, third order & 0.191 & 0.509 & -333.403 & -310.907 & 0.273 & 0.372 & 197.669 & 221.092 \\
\hline Polynomials, fourth order & 0.191 & 0.509 & -332.389 & -304.913 & 0.261 & 0.408 & 125.982 & 154.089 \\
\hline
\end{tabular}




\section{Table 3(on next page)}

Estimated parameters, $R^{2}$, and $R_{\text {adj }}^{2}$ for nonlinear growth curve model of body weight in brown frogs. 


\begin{tabular}{llllllll}
\hline \multirow{2}{*}{ Groups } & Criterion/model & \multicolumn{9}{c}{ Model parameter } & \multirow{2}{*}{$R^{2}$} & \multirow{2}{*}{$R_{\text {adj }}^{2}$} \\
\cline { 3 - 6 } & & $\mathrm{A}$ & $\mathrm{B}$ & $\mathrm{C}$ & $\mathrm{m}$ & \\
\hline Age 1 & Logistic & 3.734 & 10.640 & 0.309 & & 0.780 & 0.780 \\
& Gompertz & 4.136 & 1.102 & 0.178 & & 0.775 & 0.775 \\
& Von Bertalanffy & 4.466 & 0.679 & 0.134 & & 0.772 & 0.772 \\
& Brody & 7.058 & 1.007 & 0.043 & & 0.764 & 0.763 \\
& Richards & 3.540 & 322.379 & 0.534 & 2.736 & 0.782 & 0.781 \\
& Janoschek & 3.477 & & $2.656 \mathrm{E}-3$ & 3.542 & 0.763 & 0.762 \\
\hline Age 2 & Logistic & 19.068 & 10.265 & 0.315 & & 0.819 & 0.819 \\
& Gompertz & 20.502 & 1.107 & 0.191 & & 0.815 & 0.815 \\
& Von Bertalanffy & 21.620 & 0.685 & 0.148 & & 0.812 & 0.812 \\
& Brody & 28.703 & 1.015 & 0.060 & & 0.801 & 0.801 \\
& Richards & 18.924 & 15.683 & 0.338 & 1.194 & 0.819 & 0.819 \\
& Janoschek & 18.546 & & $3.572 \mathrm{E}-3$ & 2.460 & 0.815 & 0.814 \\
\hline
\end{tabular}




\section{Table 4 (on next page)}

Estimated parameters, $R^{2}$, and $R_{\text {adj }}^{2}$ for the linear and polynomial growth curve models of body weight in brown frogs. 
Manuscript to be reviewed

\begin{tabular}{|c|c|c|c|c|c|c|c|c|}
\hline \multirow[t]{2}{*}{ Criterion/model } & \multirow[t]{2}{*}{ Groups } & \multicolumn{5}{|c|}{ Model parameter } & \multirow[t]{2}{*}{$R^{2}$} & \multirow[t]{2}{*}{$R_{\text {adj }}^{2}$} \\
\hline & & $\mathrm{d}_{0}$ & $d_{1}$ & $\mathrm{~d}_{2}$ & $d_{3}$ & $\mathrm{~d}_{4}$ & & \\
\hline \multirow[t]{4}{*}{ Age 1} & Linear & 0.255 & 0.206 & & & & 0.755 & 0.75 \\
\hline & Polynomials, second order & -0.080 & 0.306 & $-5.283 \mathrm{E}-3$ & & & 0.766 & 0.76 \\
\hline & Polynomials, third order & 0.504 & -0.019 & $3.640 \mathrm{E}-2$ & $-1462 \mathrm{E}-3$ & & 0.782 & 0.78 \\
\hline & Polynomials, fourth order & 0.555 & $-6.304 \mathrm{E}-2$ & $4.611 \mathrm{E}-2$ & $-2.243 \mathrm{E}-3$ & $2.053 \mathrm{E}-5$ & 0.782 & 0.78 \\
\hline \multirow[t]{4}{*}{ Age 2} & Linear & 2.133 & 0.961 & & & & 0.779 & 0.77 \\
\hline & Polynomials, second order & -0.462 & 1.670 & $-3.370 \mathrm{E}-2$ & & & 0.805 & 0.80 \\
\hline & Polynomials, third order & 1.736 & 0.548 & $9.660 \mathrm{E}-2$ & $-4.136 \mathrm{E}-3$ & & 0.814 & 0.81 \\
\hline & Polynomials, fourth order & 4.4634 & -1.586 & 0.529 & $-3.558 \mathrm{E}-2$ & $0.748 \mathrm{E}-3$ & 0.822 & 0.82 \\
\hline
\end{tabular}




\section{Table 5 (on next page)}

Estimated parameters, $R^{2}$, and $R_{\text {adj }}^{2}$ for the nonlinear growth curve model of body size. 


\begin{tabular}{llllllll}
\hline \multirow{2}{*}{ Groups } & Criterion/model & \multicolumn{2}{l}{ Model parameter } & \multicolumn{2}{l}{$R^{2}$} & \multirow{2}{*}{$R_{\text {adj }}^{2}$} \\
\cline { 3 - 5 } & & $\mathrm{A}$ & $\mathrm{B}$ & $\mathrm{C}$ & $\mathrm{m}$ & & \\
\hline Age 1 & Logistic & 3.263 & 2.002 & 0.311 & & 0.909 & 0.908 \\
& Gompertz & 3.310 & 0.191 & 0.244 & & 0.909 & 0.909 \\
& Von Bertalanffy & 3.331 & 0.344 & 0.221 & & 0.908 & 0.908 \\
& Brody & 3.392 & 0.757 & 0.177 & & 0.907 & 0.907 \\
& Richards & 3.290 & 0.532 & 0.268 & 0.367 & 0.909 & 0.909 \\
& Janoschek & 3.302 & & 0.122 & 1.205 & 0.909 & 0.908 \\
\hline \multirow{2}{*}{ Age 2 } & Logistic & 5.525 & 1.094 & 0.197 & & 0.891 & 0.891 \\
& Gompertz & 5.628 & -0.253 & 0.156 & & 0.889 & 0.889 \\
& Von Bertalanffy & 5.675 & 0.232 & 0.142 & & 0.888 & 0.888 \\
& Brody & 5.794 & 0.563 & 0.115 & & 0.886 & 0.886 \\
& Richards & 5.390 & 9.331 & 0.302 & 3.436 & 0.893 & 0.893 \\
& Janoschek & 5.315 & & $1.318 \mathrm{E}-2$ & 2.069 & 0.901 & 0.901 \\
\cline { 2 - 5 } & & & & & &
\end{tabular}




\section{Table 6(on next page)}

Estimated parameters for the linear and polynomial growth curve models of body size in brown frogs. 
Manuscript to be reviewed

\begin{tabular}{|c|c|c|c|c|c|c|c|c|}
\hline \multirow[t]{2}{*}{ Criterion/model } & \multirow[t]{2}{*}{ Groups } & \multicolumn{5}{|c|}{ Model parameter } & \multirow[t]{2}{*}{$R^{2}$} & \multirow[t]{2}{*}{$R_{\text {adj }}^{2}$} \\
\hline & & $\mathrm{d}_{0}$ & $\mathrm{~d}_{1}$ & $\mathrm{~d}_{2}$ & $d_{3}$ & $\mathrm{~d}_{4}$ & & \\
\hline \multirow[t]{4}{*}{ Age 1} & Linear & 1.665 & 0.107 & & & & 0.777 & 0.777 \\
\hline & Polynomials, second order & 1.063 & 0.288 & $-9.508 \mathrm{E}-3$ & & & 0.907 & 0.907 \\
\hline & Polynomials, third order & 0.951 & 0.351 & $-1.754 \mathrm{E}-2$ & $2.819 \mathrm{E}-3$ & & 0.909 & 0.909 \\
\hline & Polynomials, fourth order & 9.220 & 0.375 & $-2.293 \mathrm{E}-2$ & $7.148 \mathrm{E}-4$ & $-1.139 \mathrm{E}-5$ & 0.909 & 0.909 \\
\hline \multirow[t]{4}{*}{ Age 2} & Linear & 3.254 & 0.127 & & & & 0.812 & 0.811 \\
\hline & Polynomials, second order & 2.671 & 0.286 & $-7.571 \mathrm{E}-3$ & & & 0.887 & 0.887 \\
\hline & Polynomials, third order & 2.592 & 0.327 & $-1.227 \mathrm{E}-2$ & $1.491 \mathrm{E}-4$ & & 0.888 & 0.888 \\
\hline & Polynomials, fourth order & 2.993 & $1.293 \mathrm{E}-2$ & $5.120 \mathrm{E}-2$ & $-4.473 \mathrm{E}-3$ & $1.100 \mathrm{E}-4$ & 0.898 & 0.898 \\
\hline
\end{tabular}

